\title{
ANÁLISE DA INFLUÊNCIA DA VELOCIDADE DE AVANÇO NO DESGASTE DA ARESTA DE UMA FERRAMENTA DE CORTE
}

\author{
Matheus Nogueira Andrade ${ }^{1}$ \\ Tiago Batista Pereira ${ }^{2}$ \\ Marcos Vieira de Souza ${ }^{3}$
}

\begin{abstract}
Resumo: Este trabalho apresenta uma análise, por meio de um estudo de caso, da influência da velocidade de avanço no desgaste da aresta de uma ferramenta de corte durante um processo de torneamento. Assim, por meio de uma revisão bibliográfica, verificou-se que diversos autores afirmam que a velocidade de avanço tem influência no desgaste das ferramentas de corte, sendo esta a motivação para a escolha de tal parâmetro de processo como o foco de estudo para este trabalho. Por fim, o trabalho apresenta a confirmação do efeito proposto pelos autores para o processo em questão, comprovando a existência de tal influência no desgaste da aresta de uma ferramenta de corte.
\end{abstract}

Palavras-chave: Desgaste da aresta; Velocidade de avanço da ferramenta; Ferramenta de corte.

\footnotetext{
${ }^{1}$ Engenharia de Produção - Centro Universitário de Itajubá, Brasil. E-mail: matheus.nogand@gmail.com.

2 Engenharia de Produção - Centro Universitário de Itajubá, Brasil. E-mail: tiago.b.p@bol.com.br.

3 Professor do Curso de Engenharia de Produção - Centro Universitário de Itajubá, Brasil. E-mail: mvs58@hotmail.com.
} 